\title{
Characterization of the Adhesion of the Human Monocytic Cell Line U937 to Cultured Endothelial Cells
}

Paul E. DiCorleto and Carol A. de la Motte

Atherosclerosis Section, Department of Cardiovascular Research, Division of Research,

The Cleveland Clinic Foundation, Cleveland, Ohio 44106

\begin{abstract}
Adhesion of blood-borne monocytes to the vascular endothelium is the first step in the infiltration of this leukocyte into the vessel wall or the interstitial space during inflammation. A significant role for the monocyte in both wound healing and atherogenesis is now well accepted. The molecular interactions involved in monocyte attachment to the endothelium are unknown. To study this phenomenon we have developed an in vitro system that uses the human monocytic tumor cell line U937 as a model for the blood-borne monocyte. ${ }^{51} \mathrm{Cr}$-labeled U937 cells were found to adhere with high affinity to cultured endothelial cells (ECs) from several sources. Much less binding was observed to either smooth muscle cells or fibroblasts from several species. Conditioned medium and cocultivation experiments ruled out the possibility that target cells could affect U937 cell binding by secretion of factors. Binding of U937 cells to porcine aortic ECs reached equilibrium after $30 \mathrm{~min}$ at $37^{\circ} \mathrm{C}$ and $90 \mathrm{~min}$ at $4^{\circ} \mathrm{C}$ with similar extent of binding at the two temperatures. Binding of U937 to the endothelium reached saturation at 9-12 U937 per porcine aortic EC (semiconfluent) with half-maximal binding at $1.5 \times 10^{6} \mathrm{U} 937 \mathrm{cells} /$ $\mathrm{ml}$. Bound cells dissociated with a half-life of $20 \mathrm{~h}$ at $37^{\circ} \mathrm{C}$. Adhesion of $\mathrm{U} 937$ cells was blocked by prior incubation of ECs with normal human monocytes but not with platelets, lymphocytes, or neutrophils. Trypsin treatment or detergent solubilization of ECs inhibited U937 cell binding. A striking effect of EC density on monocytic cell adhesion was observed with bovine, rat, and porcine ECs. Confluent cultures of these cells exhibited negligible binding of U937, but when plated sparsely, the same cells were excellent targets for U937 cell adhesion. In addition, when confluent cultures of bovine aortic ECs were "wounded" with a cotton swab and then allowed to recover for $24 \mathrm{~h}$ at $37^{\circ} \mathrm{C}$, U937 cells were found to adhere most readily to the ECs migrating into the wound and neighboring the wound but not to ECs in the confluent monolayer away from the wound edge. These latter results may have implications for the focal adhesion of monocytes to the vessel wall in vivo.
\end{abstract}

\section{Introduction}

Involvement of the blood-borne monocyte in phenomena related to vascular interactions that include wound healing

Address correspondence to Dr. DiCorleto.

Received for publication 21 June 1984 and in revised form 10 December 1984.

J. Clin. Invest.

(c) The American Society for Clinical Investigation, Inc. 0021-9738/85/04/1153/09 \$1.00

Volume 75, April 1985, 1153-1161 and atherosclerosis, though currently well recognized, remains to be defined on a molecular level. The monocyte-derived macrophage has been implicated in several aspects of atherosclerotic plaque development (1-4). First, these cells can contribute to the formation of fatty streak lesions by ingesting massive amounts of lipid and thus developing into foam cells (5-7). Second, in vitro experiments indicate that the monocyte/ macrophage is capable of producing a growth factor for vascular smooth muscle cells (SMCs), ${ }^{1}$ thus potentially contributing to the proliferative stages of plaque development $(8,9)$. Third, the monocyte/macrophage may contribute to vascular wall injury by generating cytotoxic factors for neighboring SMCs (10) or by physical damage to the endothelium during the proposed emigration of the foam cell from the intima (11).

The first step in monocyte involvement in vascular wall events is the attachment of this blood-borne cell to the endothelium. The adherence of mononuclear cells to the endothelium of large vessels during the early stages of experimentally induced atherosclerosis has been observed in many animal model systems over the years. The rigorous identification of these adherent mononuclear cells as blood-borne monocytes and a detailed temporal account of their transendothelial migration, however, has been reported only recently. These detailed studies were performed on such model systems as the hypercholesterolemic swine $(11,12)$, monkey (13), rat (14), and pigeon (15). All of these systems have yielded consistent results-a highly focal adhesion of monocytes as an early event after high-cholesterol feeding. Important points that remain unclear include the mechanism by which hypercholesterolemia causes increased adherence of monocytes to the endothelium and the reason why the monocytes adhere to specific regions of the vessel wall.

Leukocyte adhesion to the endothelium in vitro has been studied by several investigators in the past decade, but the majority of the studies have utilized mixtures of white cells (16-18), purified neutrophils (19-21), or even macrophages $(22,23)$ rather than monocytes. Neutrophils have been used extensively not only because of their importance in the initial events of the inflammatory response but presumably because of the ease with which homogenous cell populations can be obtained from whole blood. Pure populations of monocytes, on the other hand, are difficult to obtain in the absence of either an attachment step, which can cause activation of the cells, or counterflow elutriation-a high-resolution but timeconsuming technique. Large numbers of homogenous monocytes are necessary in order to extensively study the molecular interactions involved in the adhesion of monocytes to the

1. Abbreviations used in this paper: $\mathrm{DV} / \mathrm{F} 12$, complete media containing Dulbecco's modified Eagle's medium and Ham's F12; EC(s), endothelial cell(s); SMC(s), smooth muscle cell(s). 
endothelium. We decided to determine whether U937 cells (24), a human monocytelike cell line, might be used as a model for the blood-borne monocyte in endothelial cell (EC) adhesion experiments. U937 cells, which were originally derived from a diffuse histiocytic lymphoma, exhibit many characteristics of monocytes including complement and Fc receptors, phagocytic activity, sodium fluoride-sensitive esterase activity, lysozyme production, and chemotactic responsiveness to $N$-formyl-methionyl-leucyl-phenylalanine when activated (24, 25). U937 cells are advantageous in that virtually unlimited numbers of homogenous cells can be prepared (population doubling time of $20 \mathrm{~h}$ ), labeling of the cells is readily achieved with ${ }^{51} \mathrm{Cr}$ or $\left[{ }^{3} \mathrm{H}\right]$ thymidine, and, most importantly for adhesion studies, they exhibit no tendency to attach to tissue culture plastic. We have examined the target cell specificity of U937 cell attachment and have characterized the adhesion of U937 cells to cultured ECs under various conditions. Our results suggest that this monocytic cell line may be an important tool in the study of the mechanisms involved in monocyte-endothelium attachment.

\section{Methods}

Cell culture. Cultures of bovine aortic ECs, porcine aortic ECs, and human umbilical vein ECs were isolated and maintained as previously described (26). Rat heart ECs were cloned by limiting dilution of cultures derived from enzyme-perfused hearts and originally grown on a selective substratum (Primaria, Falcon Labware, Oxnard, CA). Cells were identified as ECs by nonoverlapping cobblestone culture morphology, production of a platelet-derived growth factor-like protein, and complete lack of platelet-derived growth factor receptors (26). SMCs from bovine and porcine aorta as well as human foreskin fibroblasts were obtained by the explant method of Ross (27). The above cells were maintained in a 1:1 mixture of Dulbecco-Vogtmodified Eagle's medium with high glucose and Ham's F12 (DV/F12 media) supplemented with sodium bicarbonate $(0.24 \%)$, penicillin $(100$ $\mathrm{U} / \mathrm{ml})$, streptomycin $(100 \mu \mathrm{g} / \mathrm{ml})$, nonessential amino acids $(0.1 \mathrm{mM})$, sodium pyruvate $(1 \mathrm{mM})$, and L-glutamine $(4 \mathrm{mM})$. Media and supplements were obtained from Gibco Laboratories (Grand Island, NY). Cells were subcultured with trypsin-EDTA ( $0.05 \%$ trypsin [Worthington Biochemical Corp., Freehold, NJ]/0.02\% EDTA) in $75-\mathrm{cm}^{2}$ flasks in humidified incubators, $95 \%$ air: $5 \% \mathrm{CO}_{2}$, at $37^{\circ} \mathrm{C}$. Cells were used between passages 5 and 20 except for the human umbilical vein ECs which were primary cultures. U937 cells (American Type Culture Collection, Rockville, MD) were maintained in RPMI-1640 medium (M. A. Bioproducts, Walkersville, MD) supplemented with $5 \%$ fetal bovine serum and $2 \mathrm{mM}$ L-glutamine. U937 cells were grown in suspension culture and subcultured 1:5 three times per week in 75$\mathrm{cm}^{2}$ flasks (Costar, Cambridge, MA), and always refed the day before the assay.

Assay of U937 cell adhesion. Target cells for the adhesion assay were trypsinized with trypsin-EDTA in phosphate-buffered saline for $10 \mathrm{~min}$ at $37^{\circ} \mathrm{C}$. They were washed and resuspended in DV/F12 medium with $5 \%$ fetal bovine serum to desired concentration for culture density and plated in either 24-well (Costar) or 96-well (Nunc) plates at least $18 \mathrm{~h}$ before the assay. On the day of the assay, U937 cells (up to $50 \times 10^{6} / \mathrm{ml}$ ) were labeled for $90 \mathrm{~min}$ at $37^{\circ} \mathrm{C}$ with 200 ${ }_{\mu \mathrm{Ci}}{ }^{\mathrm{i}} \mathrm{Cr}$ as $\mathrm{NaCrO}_{4}$ (New England Nuclear, Boston, MA) in $1 \mathrm{ml}$ culture media. Cells were washed three times with culture media, counted on a hemacytometer, and resuspended to the necessary concentration per assay. The labeled U937 cells were incubated with target cells at $4^{\circ} \mathrm{C}$ for $2 \mathrm{~h}$ unless otherwise noted. At the end of the incubation, the wells were alternately filled with culture media and aspirated three times to remove unbound U937 cells. Sodium dodecyl sulfate $\left(0.1 \%\right.$ solution) was then added and incubated at $37^{\circ} \mathrm{C}$ to disrupt cells, and an aliquot was removed and counted in a gamma counter (Beckman gamma 4000, Beckman Instruments, Inc., Fullerton, CA). At the same time, untreated multiple wells of target cells were trypsinized and counted on a hemacytometer to determine the actual number of targets per well. The number of U937 cells bound per well was calculated from the specific activity (counts per minute $/ 10^{5}$ cells) of the U937 cell preparation and then divided by the number of target cells per well at the end of the washing procedure to obtain number of U937 cells bound per target cell. All data points represent a minimum of triplicate determinations with standard error of $<10 \%$. Residual U937 cells not removed from empty wells by the washing procedure represented $<2 \%$ of the bound U937 cells in a typical experiment. Spontaneous release of label was usually $<5 \%$ of total counts after the 2-h adhesion assay, and of that spontaneously released ${ }^{51} \mathrm{Cr}$, only a negligible amount $(0.2 \%)$ was able to reassociate with the target cells in a subsequent 2-h incubation at $4^{\circ} \mathrm{C}$.

Purification of leukocytes. Peripheral blood was collected by sterile venipuncture from healthy human volunteers into heparinized $(20$ $\mathrm{U} / \mathrm{ml}$ of blood) syringes. Mononuclear cells were separated by the method of Boyum (28). Briefly, whole blood $(15 \mathrm{ml})$ was diluted with $15 \mathrm{ml}$ of PBS, underlayered with $15 \mathrm{ml}$ of Ficoll-Hypaque (Pharmacia Fine Chemicals, Piscataway, NJ), and centrifuged at $440 \mathrm{~g}$ for $30 \mathrm{~min}$. After centrifugation the cells at the Ficoll interface were collected and washed three times with PBS. Total viable mononuclear cell number was determined by hemacytometer count in the presence of trypan blue dye. The total cell pellet was resuspended in $5 \mathrm{ml}\left(250 \times 10^{6}\right.$ cells $/ \mathrm{ml}$ ) of Krebs-Ringer buffer with $0.25 \%$ bovine serum albumin for centrifugal elutriation as follows:

Fractions of mononuclear cells were isolated using a Beckman J221 centrifuge equipped with a JE-6 elutriation and rotor system by published methods $(29,30)$. Rotor speed was fixed at $2,030 \mathrm{rpm}$ and held at $12^{\circ}-18^{\circ} \mathrm{C}$. Flow rates started at an initial rate of $7.0 \mathrm{ml} / \mathrm{min}$ (Cole-Parmer Master Flex Pump, Cole-Parmer Instrument Co., Chicago, IL) and increased in steps up to $30 \mathrm{ml} / \mathrm{min}$. 50-150-ml fractions were collected in 50-ml centrifuge tubes on ice. Cells were washed twice, resuspended in DV/F12 medium containing $5 \%$ fetal bovine serum, and counted for viable cells using trypan blue exclusion and a hemacytometer. The differential composition of each fraction was determined on cytocentrifuge preparations by May Grunwald Giemsa stain, and blindly scored for monocytes by two experienced technicians. The scoring method has been found to yield numbers of monocytes which are in good agreement with those obtained by latex particle phagocytosis and nonspecific esterase staining. In addition, the elutriation results in terms of elution patterns of platelets, lymphocytes, and monocytes are very similar to the published results of others using fixed rotor speed (30).

Neutrophils were prepared according to the method of Stossel et al. (31), utilizing Ficoll-Hypaque gradient centrifugation, dextran sedimentation, and hypotonic lysis of erythrocytes.

\section{Results}

Specificity of U937 cell attachment to cultured cells. The use of U937 cells in studies of cell-cell attachment in vitro are facilitated by the fact that this monocytic cell line does not adhere to tissue culture plastic. When the U937 cells were incubated with various cultures of vascular cells and fibroblasts, a striking degree of specificity of binding was observed. As shown in Table I, porcine aortic ECs represented the best target for U937 cell attachment, whereas several types of fibroblasts and aortic SMCs exhibited much less binding. In the case of these latter two cell types, phase-contrast microscopy confirmed a low level of U937 cell attachment that is evenly distributed over the entire culture. Human umbilical vein ECs, on the other hand, exhibited a low level of binding, but adhesion of U937 cells was quite heterogenous with a small 
Table I. Comparison of U937 Cell Adhesion to Various Cell Types

\begin{tabular}{llll}
\hline & \multicolumn{2}{l}{ Number of U937 cells bound per target cell } \\
\cline { 2 - 4 } Target cell & Exp. 1 & Exp. 2 & Exp. 3 \\
\hline & $n$ & $n$ & $n$ \\
$\begin{array}{l}\text { Porcine aortic ECs } \\
\begin{array}{l}\text { Human umbilical } \\
\text { vein ECs }\end{array}\end{array}$ & $2.9 \pm 0.06$ & $3.3 \pm 0.11$ & $9.0 \pm 0.43$ \\
$\begin{array}{l}\text { BALB 3T3 } \\
\text { Human fibroblasts }\end{array}$ & $0.2 \pm 0.03$ & $0.4 \pm 0.03$ & $0.7 \pm 0.06$ \\
$\begin{array}{l}\text { Porcine aortic } \\
\text { SMCs }\end{array}$ & $0.3 \pm 0.01$ & - & - \\
Bovine aortic & $0.1 \pm 0.01$ & - & - \\
$\quad \begin{array}{l}\text { SMCs } \\
\text { Bovine aortic ECs }\end{array}$ & - & $0.1 \pm 0.01$ & $2.0 \pm 0.02$ \\
& - & - & $0.4 \pm 0.01$ \\
\end{tabular}

All target cells were plated at high cell density leading to near-confluent cultures at the time of the adhesion assay $18 \mathrm{~h}$ later. The adhesion assays were performed at $4^{\circ} \mathrm{C}$ as described in Methods, and results are expressed as the mean $(n \geq 3) \pm \mathrm{SE}$.

fraction of ECs binding 10 or more U937 cells, and the majority of ECs binding none. All target cells in this series of experiments (Table I) were utilized at near confluence which explains the low number of U937 cells attached to bovine aortic ECs (see later subsection in Results and Fig. 3). With all of the cell types tested, binding of U937 cells was observed by microscopy to be to the cell surface exclusively and not to any space between cells.

Conditioned medium and co-cultivation experiments were performed in order to test the possibility that target cells could affect U937 cell binding by the secretion of factors. We found no evidence for the release of binding stimulators by ECs or binding inhibitors by SMCs. In Table II, binding of U937 to porcine aortic ECs was unaffected by an 18-h preincubation

Table II. Effect of Conditioned Media on U937 Cell Adhesion to Porcine Aortic ECs and Bovine Aortic SMCs

\begin{tabular}{lll}
\hline & \multicolumn{2}{l}{ Number of U937 cells bound per target cell } \\
\cline { 2 - 3 } $\begin{array}{l}\text { Cell type for } \\
\text { conditioned media }\end{array}$ & Porcine aortic ECs & Bovine aortic SMCs \\
\hline & $n$ & $n$ \\
No cells & $1.9 \pm 0.04$ & $0.19 \pm 0.01$ \\
Human fibroblasts & $1.7 \pm 0.04$ & $0.20 \pm 0.02$ \\
Porcine aortic ECs & $1.9 \pm 0.02$ & $0.22 \pm 0.01$ \\
Bovine aortic ECs & $2.0 \pm 0.03$ & $0.20 \pm 0.01$ \\
Bovine SMCs & $1.4 \pm 0.15$ & -
\end{tabular}

All conditioned media represented $24-\mathrm{h}$ collections of DV/F12 media containing $5 \%$ fetal bovine serum. The actual cultures from which media were collected were tested for U937 cell binding and very low binding was observed to the SMC and fibroblast cultures and high binding to the semi-confluent EC cultures. Replicate wells of target cells, porcine aortic ECs, and bovine aortic SMCs were plated at $10^{5}$ and $2 \times 10^{5}$ cells, respectively, per 24-well plate and incubated for 6 $h$ at $37^{\circ} \mathrm{C}$. Plating medium was then replaced with conditioned media for overnight incubation. $18 \mathrm{~h}$ later a U937 cell adhesion assay was performed as described in Methods and the number of U937 cells bound (mean $\pm \mathrm{SE}$ ) was calculated. with conditioned medium from confluent cultures of bovine aortic SMCs or human foreskin fibroblasts-neither of which bind U937. In addition, attachment of the U937 cells to bovine aortic SMCs was unaffected by an 18-h preincubation with conditioned medium from three high-binding cellsporcine and bovine aortic ECs (Table II) and rat heart ECs (not shown). High-binding cells (porcine aortic ECs) and lowbinding cells (bovine aortic SMCs and human fibroblasts) were individually cultured on plastic coverslips and allowed to attach overnight. The following day the coverslips were incubated in various combinations in single petri dishes so that the different cell types were bathed in the same medium. U937 cells were then added to the petri and after a normal binding incubation, coverslips were individually washed and adhesion of U937 cells was determined. Binding of U937 cells to any single cell type was unaffected by the presence of other target cells in the same dish. Therefore co-cultivation results were completely consistent with the conditioned medium experiment (Table II).

Characterization of U937 cell binding to cultured ECs. The time course for binding of U937 cells to porcine aortic ECs was examined at two temperatures (Fig. 1). Cell-cell adhesion reached equilibrium within $15 \mathrm{~min}$ at $37^{\circ} \mathrm{C}$ and $90 \mathrm{~min}$ at $4^{\circ} \mathrm{C}$. The extent of U937 cell attachment per porcine aortic (Fig. 1) or human umbilical vein ECs (not shown) was equivalent at the two temperatures at equilibrium. The target cells exhibited no loss in viability during the $4^{\circ} \mathrm{C}$ incubation as evidenced by exclusion of vital dyes and by normal cell morphology under phase-contrast microscopy. In all subsequent experiments unless otherwise stated, binding assays were performed at $4^{\circ} \mathrm{C}$ in order to avoid possible complications due to cellular release of modulating compounds and in order to examine only the initial event in cell-cell interaction, i.e., the binding step.

We examined the saturability of U937 cell binding to semiconfluent porcine aortic ECs by increasing the number of monocytic cells in the incubation (Fig. 2). Half-maximal binding was achieved at $1.5 \times 10^{6} \mathrm{U} 937$ cells $/ \mathrm{ml}$ with a maximal attachment of approximately nine U937 cells per EC. Though cell-cell binding represents a highly complex process, it is interesting to note that Scatchard analysis of the

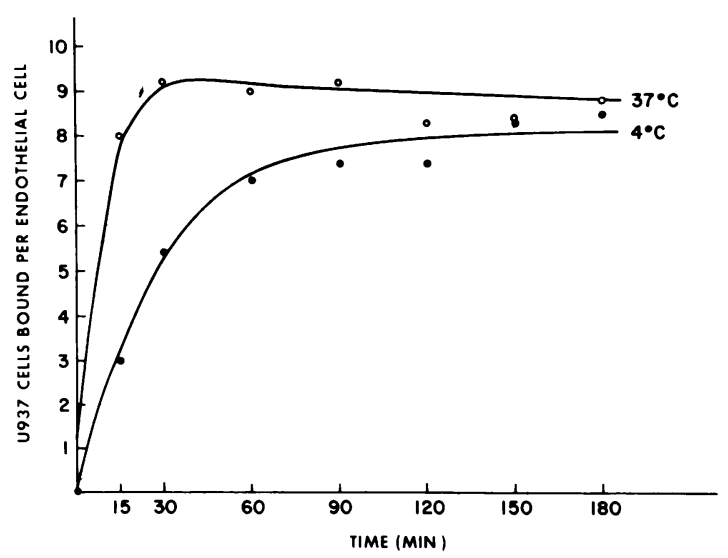

Figure 1. Time course of binding of U937 cells to porcine aortic ECs at $4^{\circ} \mathrm{C}(\bullet)$ and $37^{\circ} \mathrm{C}(0)$. Adhesion of U937 cells was determined as described in Methods. Porcine EC density in the 24-well plates was $1.2 \times 10^{5}$ cells/well. 


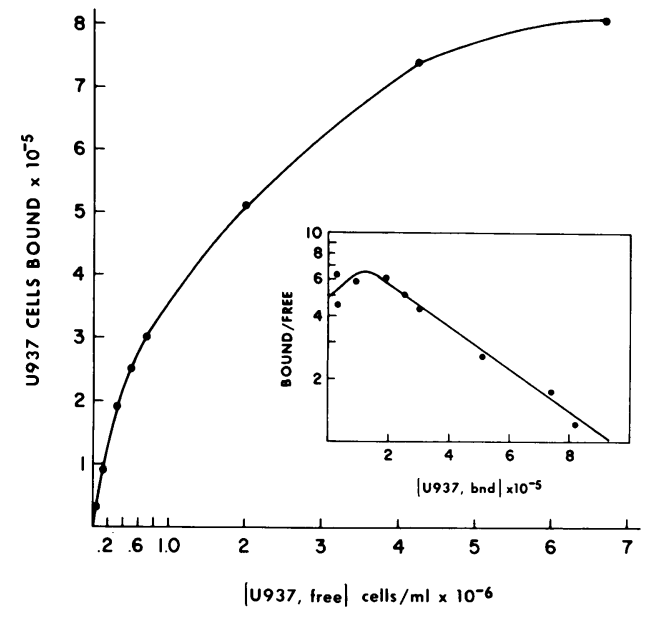

Figure 2. Effect of U937 cell number on adhesion to porcine aortic ECs. A routine adhesion assay was performed; however, the number of ${ }^{51} \mathrm{Cr}$-labeled U937 cells in the incubation was varied as shown. The number of ECs in the replicate wells (24-well plate) was $10^{5}$ cells. (Inset) Data from the binding curve was subjected to Scatchard analysis.

data (Fig. 2, inset) yields a linear plot over a wide range of U937 cell concentrations with a region of nonlinearity at low concentrations. The reversibility of U937 cell adhesion to ECs was examined at $4^{\circ} \mathrm{C}$ but the time required to detect measurable levels of dissociation $(>4 \mathrm{~h}$ ) caused the ECs to begin to detach from the plastic. Dissociation of U937 cells was therefore measured at $37^{\circ} \mathrm{C}$, at which temperature, however, the monocytic cells spread on the target surface. The $t_{1 / 2}$ for dissociation was found to be $\sim 20 \mathrm{~h}$ under these conditions. Spontaneous release of label under the experimental conditions was determined at each time point and used to correct the value for U937 cell dissociation.

Microscopy had verified that, in all of the above experiments, U937 cells were associated with cells rather than exposed intercellular substratum. To further rule out the possibility that U937 cells were binding to a component of the extracellular matrix, cultures of porcine aortic ECs were treated with Triton X-100 as described by Gospodarowicz and Ill (32) in order to solubilize all cell surface receptors and leave on the plastic a cell-derived matrix (and possibly cytoskeleton). As shown in Table III, Triton solubilization led to an $88 \%$ decrease in U937 cell binding. In a separate experiment porcine aortic ECs were removed from the substratum by EDTA treatment, and U937 cell adhesion was found to be inhibited by $\sim 80 \%$. The trypsin sensitivity of the cell-cell attachment was also examined and results are shown in Table III. Pretreatment of U937 cells with this protease led to no loss in ability to bind to ECs. Trypsin treatment of the ECs led to an apparent inhibition in subsequent adhesion of U937 cells.

Blocking of U937 cell adhesion to ECs by blood monocytes but not by other leukocytes. We wished to determine whether freshly isolated blood-borne monocytes would bind to cultured ECs in such a way as to specifically inhibit subsequent U937 cell adhesion. A cell-cell attachment competitive assay was developed that is analogous to radioreceptor assays for polypeptide hormones. Human leukocytes were fractionated by a combination of Ficoll density centrifugation and counterflow
Table III. Effect of Triton X-100 Solubilization and Trypsin Treatment on U937 Cell Adhesion to Porcine Aortic ECS

\begin{tabular}{lll}
\hline EC treatment & U937 treatment & $\begin{array}{l}\text { Number of U937 cells } \\
\text { bound per EC }\end{array}$ \\
\hline & & $n$ \\
None & None & $3.2 \pm 0.06$ \\
Triton X-100 (1\%) & None & $0.4 \pm 0.00$ \\
Trypsin $(0.25 \%)$ & None & $1.8 \pm 0.10$ \\
None & $0.25 \%$ Trypsin & $3.3 \pm 0.03$ \\
\hline
\end{tabular}

Porcine aortic ECs were plated at $10^{5}$ cells/well of a 24-well plate in DV/F12 media plus 5\% fetal bovine serum. After overnight incubation, four wells were treated with either trypsin or Triton X-100 for 5 min at room temperature and then washed with serum containing media. An aliquot of labeled U937 cells was similarly treated with trypsin. A U937 cell adhesion assay was performed; data are expressed as mean $\pm \operatorname{SE}(n=4)$.

elutriation. Fractions that contained a majority of platelets and/or lymphocytes exhibited no ability to block subsequent binding of U937 cells to ECs (Table IV). Though some lymphocyte binding to the monolayer was observed after the preincubation, no inhibition in subsequent U937 cell binding was observed. Elutriated fractions containing a large percentage of monocytes were able to efficiently block the subsequent binding of U937 cells as determined both visually and by use of labeled U937 cells (Table IV). Binding of U937 cells to ECs was very high in this study due to the sparse cultures used in the experiment (see next subsection). The blood monocytes were at least as potent on a per cell basis as unlabeled U937

Table IV. Ability of Normal Human Leukocytes to Block the Adhesion of U937 Cells to Porcine and Bovine Aortic ECS

\begin{tabular}{llll}
\hline & & \multicolumn{2}{l}{$\begin{array}{l}\text { Number of U937 cells } \\
\text { bound per target cell }\end{array}$} \\
\cline { 3 - 4 } Competitor & Monocytes & $\begin{array}{l}\text { Porcine } \\
\text { aortic ECs }\end{array}$ & $\begin{array}{l}\text { Bovine } \\
\text { aortic ECs }\end{array}$ \\
\hline & \% of total & $n$ & $n$ \\
None & & & \\
U937 cells & & $22.7 \pm 1.18$ & $27.3 \pm 1.47$ \\
Total mononuclear & & $14.2 \pm 0.36$ & $12.9 \pm 0.52$ \\
$\quad$ cells & 22 & & \\
Fraction 1 & 0 & $21.3 \pm 0.56$ & $19.9 \pm 1.07$ \\
Fraction 2 & 3 & $25.0 \pm 0.45$ & $25.3 \pm 1.72$ \\
Fraction 3 & 26 & $24.8 \pm 0.57$ & $22.7 \pm 0.98$ \\
Fraction 4 & 30 & $24.6 \pm 0.56$ & $28.0 \pm 1.04$ \\
Fraction 5 & 48 & $21.6 \pm 0.32$ & $20.7 \pm 1.02$ \\
Fraction 6 & 55 & $20.7 \pm 0.86$ & $24.6 \pm 1.07$ \\
Fraction 7 & 85 & $17.7 \pm 0.30$ & $14.7 \pm 0.92$ \\
& & $13.6 \pm 0.41$ & $15.4 \pm 1.38$ \\
& & &
\end{tabular}

Mononuclear cells were subjected to centrifugal elutriation as described in Methods. Each fraction was counted by hemacytometer and $2 \times 10^{5}$ viable mononuclear cells or unlabeled U937 cells were incubated in replicate wells of each sparse target type in 96-well plates for $2 \mathrm{~h}$ at $4^{\circ} \mathrm{C}$. Wells were then filled with media and aspirated three times to remove nonattached leukocytes. Then ${ }^{51} \mathrm{Cr}$-labeled U937 cells $\left(2 \times 10^{5}\right)$ were added to each well, and plates were again incubated at $4^{\circ} \mathrm{C}$ for $2 \mathrm{~h}$ as in a routine adhesion assay. Fraction 1 contained primarily platelets. In all other fractions the cells that were not identified as monocytes were $>\mathbf{9 0 \%}$ lymphocytes by differential staining. 
cells in blocking adhesion. Polymorphonuclear leukocytes, prepared as described in Methods, also exhibited little binding to ECs and no blocking of subsequently added U937 cells (Table V). Adhesion of elutriated monocytes was found to exhibit the same target cell specificity as U937 cells, i.e., high degree of binding to pig aortic ECs but low binding to bovine aortic SMCs and much greater adhesion to sparse bovine aortic ECs than confluent cultures (data not shown).

Effect of EC density and migration on U937 cell adhesion. Adhesion of U937 cells to bovine aortic ECs was found to be very low in our initial studies (Table I) in which all cells were near confluence. To examine the possibility that U937 cell adhesion is a function of EC density, we varied the plating density of the target cell. As shown in Fig. 3 both bovine and porcine aortic ECs when sparse are excellent targets for U937 cell attachment, but binding sites are no longer apparent as the cells reach confluence. This phenomenon appears to be a general one as shown in Table VI. All of the target cells that we have tested that are positive for U937 cell attachment exhibit more binding sites per cell when sparse than when confluent. The effect of density can also be demonstrated by a different approach in which an equal number of target cells are plated in the same media either in a bubble within a well ( $\simeq 33 \%$ of the surface area of the well) or in the entire well. During the U937 binding assay the bubble culture is flooded with the monocytic cell suspension. U937 cell attachment is much greater to the ECs distributed throughout the well than to the same number that had been plated in a smaller area (Table VII). If the target cells that had been plated in a bubble were allowed to attach and spread for a few hours followed by rinsing and flooding of the well with fresh media, then during a subsequent overnight incubation, the cells on the edge of the confluent patch of cells began to migrate into the surrounding cell-free plastic. Incubation of these cultures with U937 cells led to adhesion of the monocytic cell to the migrating ECs but not to the confluent regions of the culture or the surrounding plastic (Table VII).

Confluent cultures of target cells were subjected to a wounding procedure using a cotton swab. Approximately 40$50 \%$ of the cells were removed from the well. After a recovery period of approximately $18 \mathrm{~h}$, the wounded cultures were compared with control wells in terms of U937 cell attachment. As shown in Table VIII, a significantly larger

Table V. Effect of Polymorphonuclear Leukocytes on U937 Cell Adhesion to ECs

\begin{tabular}{lll}
\hline & \multicolumn{2}{l}{$\begin{array}{l}\text { Number of U937 cells bound per } \\
\text { target cell }\end{array}$} \\
\cline { 2 - 3 } Competitor & $\begin{array}{l}\text { Porcine } \\
\text { aortic ECs }\end{array}$ & $\begin{array}{l}\text { Bovine } \\
\text { aortic ECs }\end{array}$ \\
\hline & $n$ & $n$ \\
None & & $n$ \\
U937 cells & $22.7 \pm 1.44$ & $28.4 \pm 0.80$ \\
Polymorphonuclear leukocytes & $10.6 \pm 0.37$ & $15.2 \pm 0.35$ \\
& $25.2 \pm 1.00$ & $23.7 \pm 0.48$ \\
\hline
\end{tabular}

Neutrophil (polymorphonuclear leukocyte) competitor activity was determined in an identical assay to that described for mononuclear cells in the fcotnote to Table IV.

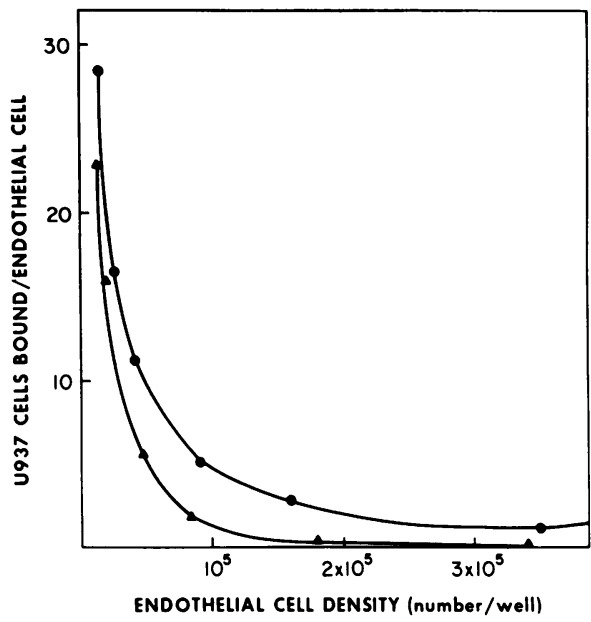

Figure 3. Effect of porcine aortic (๑) and bovine aortic (₫) EC density on the adhesion of U937 cells. Target cells were plated at various densities $18 \mathrm{~h}$ before the adhesion assay. The abscissa represents target cell counts of replicate wells (24-well plate) after the assay procedure.

number of U937 cells bound to the wounded cultures when expressed per target cell even though this average includes the cells of the confluent monolayer away from the wound. The results were more remarkable using phase-contrast microscopy (Fig. 4) in which it was clear that the U937 cells were attaching nearly exclusively to the migrating cells near the wound edge and not to the confluent monolayer away from the wound. The exposed plastic of the wound was free of U937 cells away from the wound edge but unlike sparse cultures of ECs, some monocytic cells can be seen to be attached to plastic near the migrating ECs.

Table VI. Effect of Target Cell Density on the Adhesion of U937 Cells

\begin{tabular}{lll}
\hline Target cell & $\begin{array}{l}\text { Number of target } \\
\text { cells per well }\end{array}$ & $\begin{array}{l}\text { Number of U937 cells } \\
\text { bound per target cell }\end{array}$ \\
\hline & $n$ & $n$ \\
Porcine aortic ECs & $1.3 \times 10^{5}$ & $1.7 \pm 0.13$ \\
Bovine aortic ECs & $3.1 \times 10^{4}$ & $20.1 \pm 1.55$ \\
& $2.5 \times 10^{5}$ & $0.5 \pm 0.01$ \\
Rat heart ECs & $6 \times 10^{4}$ & $3.3 \pm 0.29$ \\
Human fibroblasts & $9.3 \times 10^{4}$ & $0.9 \pm 0.03$ \\
& $2.2 \times 10^{4}$ & $8.5 \pm 0.51$ \\
Bovine aortic SMCs & $1.7 \times 10^{5}$ & $0.7 \pm 0.04$ \\
& $5.0 \times 10^{4}$ & $1.7 \pm 0.09$ \\
& $2.4 \times 10^{5}$ & $0.2 \pm 0.02$ \\
& $5.5 \times 10^{4}$ & $0.8 \pm 0.01$ \\
\hline
\end{tabular}

Target cells were suspended in DV/F12 media $+5 \%$ fetal bovine serum and plated at the indicated density in 24-well plates. Cultures were incubated $18-24 \mathrm{~h}$ at $37^{\circ} \mathrm{C}$ and then a U937 cell adhesion assay was performed. Results are expressed as the mean $\pm \mathrm{SE}$. 
Table VII. Effect of Target Cell Migration from a Confluent Culture on U937 Cell Adhesion

\begin{tabular}{lll}
\hline Target cell & Culture condition & $\begin{array}{l}\text { Number of U937 cells } \\
\text { bound per target cell }\end{array}$ \\
\hline Porcine aortic ECs & Sparse & $3.3 \pm 0.07$ \\
& Confined confluent & $0.1 \pm 0.01$ \\
& Migrating from confluent & $2.4 \pm 0.18$ \\
Bovine aortic ECs & Sparse & $0.7 \pm 0.06$ \\
& Confined confluent & $0.1 \pm 0.01$ \\
& Migrating from confluent & $2.2 \pm 0.23$
\end{tabular}

Target cells $\left(5 \times 10^{4}\right)$ were suspended in DV/F12 $+5 \%$ fetal bovine serum and plated $18 \mathrm{~h}$ prior to the adhesion assay. Cells were either seeded in $0.5 \mathrm{ml}$ per well (sparse cultures) or in a $0.1-\mathrm{ml}$ drop or bubble culture in the center of the well (24-well plate). Half the latter cultures were given an additional $0.4 \mathrm{ml}$ of media per well to flood the well following a $2-\mathrm{h}$ incubation at $37^{\circ} \mathrm{C}$ to allow attachment. Incubation was then continued at $37^{\circ} \mathrm{C}$ until the adhesion assay (migrating from confluent). The remaining bubble cultures were not flooded until the time of the adhesion assay (confined confluent).

\section{Discussion}

Leukocyte interaction with the endothelium has been the subject of much research in the past few years due to the importance of this phenomenon in the processes of inflammation, wound healing, and atherogenesis. Tissue culture systems have been developed by others to study leukocyte-EC attachment but most reports have involved the use of either purified neutrophils or unfractionated white cells (16-21). Adhesion studies with purified monocytes have been rare, perhaps due to the difficulty in obtaining adequate numbers of homogenous cell populations in the absence of an adhesion step. An in vitro system to study monocyte-EC attachment would be of great use in defining the molecular events that occur when these two cells interact on the vessel wall. The

Table VIII. Effect of Wounding of Confluent EC Cultures on U937 Cell Adhesion

\begin{tabular}{llll}
\hline Target cell & Condition & $\begin{array}{l}\text { Number of U937 cells } \\
\text { bound per target cell }\end{array}$ & $\begin{array}{l}\text { Fold } \\
\text { increase }\end{array}$ \\
\hline Porcine aortic ECs & $\begin{array}{l}\text { Confluent } \\
\text { Wounded }\end{array}$ & $\begin{array}{l}2.3 \pm 0.10 \\
5.0 \pm 0.12\end{array}$ & 2.2 \\
& Confluent & $0.5 \pm 0.04$ & \\
Rat heart ECs & Wounded & $2.1 \pm 0.00$ & 4.2 \\
& Confluent & $0.3 \pm 0.03$ & \\
Bovine aortic ECs & Wounded & $2.3 \pm 0.05$ & 7.7 \\
& & & \\
\hline
\end{tabular}

Target cells $\left(3 \times 10^{5} /\right.$ well in 24-well plates) were inoculated in DV/ $\mathrm{F} 12+5 \%$ fetal bovine serum. After $6 \mathrm{~h}$ in culture at $37^{\circ} \mathrm{C}$, an $\mathrm{x}$ was removed from the cell sheet of half the wells by use of a sterile cotton swab. Treatment removed $\sim 40-50 \%$ of the cell sheet. The media was changed in all wells and the plates were incubated at $37^{\circ} \mathrm{C}$ overnight. A routine $U 937$ cell adhesion assay was then performed. Data are means $\pm \mathrm{SE}$ system we have described in this paper that uses U937 cells as a model for the normal monocyte allows for a rapid, quantitative, and highly reproducible measure of the adhesion of a monocytic cell to cultured endothelium. Multiple observations involving many variables can be made by using numbers of U937 cells equivalent to monocytes derived from hundreds of liters of blood. Interesting findings can then be verified in a limited series of experiments by using blood monocytes that have been prepared by counterflow elutriation. To this point, as discussed in more detail below, we have found no discrepancies between results obtained with U937 cells and those obtained by us and others using blood monocytes.

The higher degree of binding of U937 cells to ECs rather than other target cell types has been recently reported by others in preliminary form (33). These investigators found significant binding of U937 cells to human umbilical vein ECs but not to bovine aortic ECs. The latter result may have been due to the use of confluent cells which exhibit very few binding sites. The specificity of binding to ECs could be due to several mechanisms. We favor the possibility that only ECs under specific culture conditions mimic situations in vivo by expressing large numbers of receptors or binding sites for the monocyte. ECs do not appear to secrete factors that cause an activation or general "stickiness" of U937 cells as evidenced by the lack of adhesion to substratum between sparse ECs and a lack of increased adhesion to poorly binding target cells in co-cultivation experiments. The latter experiments as well as conditioned media studies also indicate that those cell types that exhibit little tendency to bind U937 cells are not secreting inhibitors of adhesion. The possibility also existed that U937 cells that are of human origin would exhibit species specificity in line with an immune system cell, thus recognizing genetically incompatible (xenogeneic) cells but not homologous cells. This appears to not be the case in that good binding is observed to human ECs, especially passaged, spare cells and pig ECs but not to human fibroblasts or pig smooth muscle cells. The pig ECs, in our hands, represent the best target for monocyte adhesion, which may reflect their slow approach to a saturation density, quiescent monolayer. As discussed later, EC cultures with a small growth fraction, e.g., human umbilical vein ECs and bovine aortic ECs at confluence, express few binding sites for monocytes compared with proliferating cultures of ECs. We cannot totally rule out the possibility that the U937 cell, which is tumor-derived, is exhibiting EC specificity as a reflection of its metastatic tendencies. Other tumor cells have been shown to possess just such a specificity of attachment (34). The fact that blood monocytes are able to block the U937 cell adhesion makes the metastasizing cell hypothesis less likely.

We chose to perform most of our adhesion studies at $4^{\circ} \mathrm{C}$, because the extent of binding was comparable to that at $37^{\circ} \mathrm{C}$, and we wished to study only the initial event in the interaction of the monocytic cell with the endothelium. In analogy to studies with polypeptide hormones, in which measurements in the cold allow for the determination of receptor number in the absence of internalization and degradation, we felt that events subsequent to binding of the $\mathrm{U} 937$ cells at $37^{\circ} \mathrm{C}$, such as spreading and migration, would only complicate characterization of the binding phenomenon. The low temperature would also inhibit the secretion of modulating compounds by 

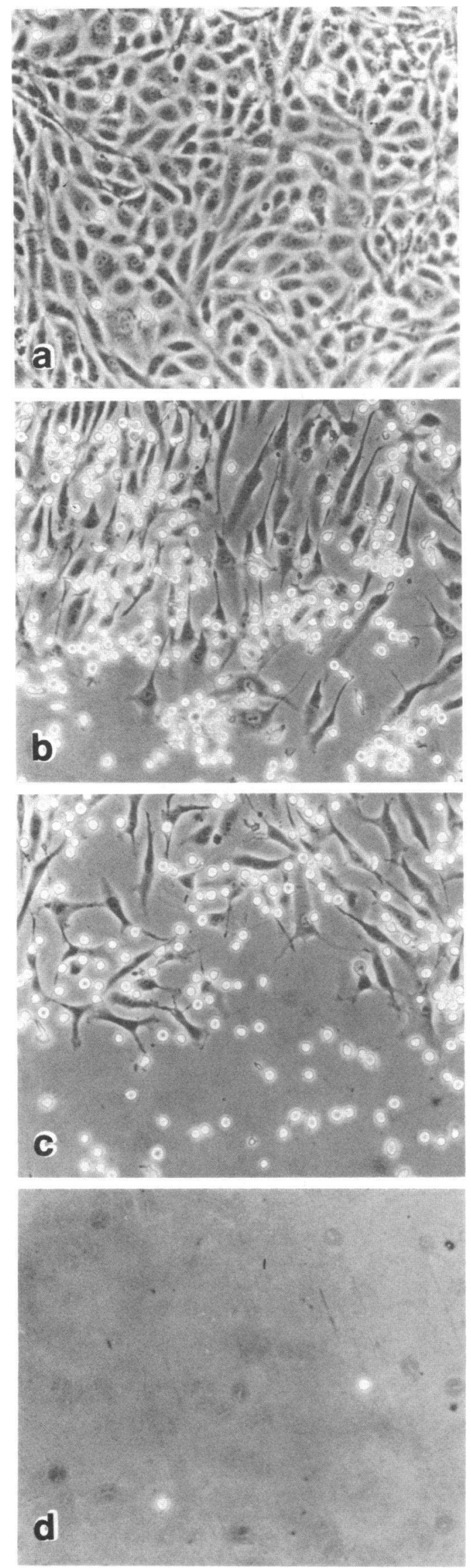

either the monocytic cells or target cells. We found that spreading of the U937 cell on the EC surface did occur at $37^{\circ} \mathrm{C}$ and that the spread cells were much less readily dissociated from the EC monolayer by mild acid treatment $(0.1 \%$ acetic acid, $0.9 \% \mathrm{NaCl}$ ) than were $\mathrm{U} 937$ cells bound at $4^{\circ} \mathrm{C}$ (unpublished observation). This result would imply that at $37^{\circ} \mathrm{C}$ additional and/or different binding interactions are generated between the two cells subsequent to the initial binding event. Another advantage of performing adhesion studies at $4^{\circ} \mathrm{C}$ is that even the normal blood monocyte, which readily attaches to plastic at $37^{\circ} \mathrm{C}$, will not bind to cell-free substratum in the cold.

The ability of blood-borne monocytes isolated by centrifugal elutriation to block subsequent adhesion of U937 cells to ECs is consistent with the idea that the two cells use the same binding site on the ECs. A caveat to this interpretation is the inability to rule out the possibility that monocytes and U937 cells may have distinct binding sites on the EC surface but the binding of one cell physically precludes the binding of the other. The saturability of U937 cell binding to ECs in fact reflects somewhat of a close packing of the monocytic cell on the EC surface. For this reason the competition assays between leukocytes and U937 cells were performed at subsaturating concentrations of cells. In addition, though the cross-sectional surface area of the monocyte is only $\sim 5 \%$ of that of a U937 cell, a quantitatively comparable amount of blocking is achieved by the two cell types when expressed per cell number. We therefore feel that the reduction in binding of labeled U937 cells to ECs after preincubation with unlabeled U937 or normal monocytes reflects a decrease in the concentration of available binding sites-analagous to radioreceptor assays established for polypeptide hormones such as the platelet-derived growth factor (35) and epidermal growth factor (36). Further evidence that monocytes block U937 cell binding by filling the same site include $(a)$ the specificity of this inhibition (i.e., does not occur with other leukocytes, including lymphocytes, which exhibit some binding to the ECs), (b) comparable target cell specificity, and $(c)$ comparable density-dependent attachment to ECs. Certainty will only be achieved, however, when the molecular moieties involved in the adhesion step are completely defined for both U937 cells and monocytes and biochemical identity is demonstrated.

The focal adhesion of monocytes to the vessel wall during atherogenesis could be explained by several separate or interdependent phenomena. Changes might occur to the endothelial surface in response to hemodynamic variables in specific regions of the arterial tree, or, due to the same forces, chemoattractant substances may be released by vessel wall cells

Figure 4. Phase-contrast photomicrographs of U937 cell adhesion to a wounded culture of bovine aortic ECs. Densely plated $\left(10^{5}\right.$ cells/ $\mathrm{cm}^{2}$ ) bovine aortic ECs were incubated for $5 \mathrm{~h}$ at $37^{\circ} \mathrm{C}$ in a six-well plate. Cells were then removed from approximately one-half of each well with a sterile cotton swab. Each well was rinsed with fresh media and then incubation continued for $16 \mathrm{~h}$ at $37^{\circ} \mathrm{C}$. An adhesion assay was then performed by adding $5 \times 10^{6} \mathrm{U} 937$ cells/well in $2 \mathrm{ml}$ of media. After $2 \mathrm{~h}$ at $4^{\circ} \mathrm{C}$ wells were washed and fresh media added for phase-contrast microscopy. Photographs are of representative fields from $(a)$ the confluent monolayer away from the wound edge, (b) cells at wound edge, $(c)$ cells and exposed plastic near the wound edge, and $(d)$ exposed plastic away from the wound edge. 
$(37,38)$, thus leading to activation and attachment of circulating monocytes. Alternatively, dying cells may express more binding sites for the monocyte. Binding of monocytic cells to dead ECs that are still attached to the vessel wall has been described $(39,40)$. In agreement with the in vivo monocyte results of Joris et al. (14), we have found that the ECs to which multiple U937 cells adhere are viable by vital dye exclusion, by morphology, and by the fact that they remain attached to substratum after a rigorous washing procedure. Recent studies by others have indicated that monocytes most readily adhere to ECs that are regenerating in response to an experimental mechanical injury in hypercholesterolemic rabbits (41). We have demonstrated a much greater degree of binding of U937 cells to ECs that are migrating into a mechanically generated "wound" in a confluent culture.

A density-dependent adhesion of peritoneal macrophages to cultured aortic ECs has been described recently by others (22). Our studies on sparse vs. confluent ECs, as well as the wounding experiments, indicate that monocytes also exhibit a greater tendency to adhere to sparse vs. confluent ECs. Two possible mechanisms for increased binding of monocytes to sparse ECs are an increased expression of monocyte binding sites when ECs are either $(a)$ actively migrating or $(b)$ proliferating in response to a stimulus. EC exhibit a stringent contact-inhibited culture morphology with a striking degree of saturation density inhibition of growth, i.e., confluent cultures, similar to the in vivo situation, exhibit a very small growth fraction (42). In addition, free migration of individual ECs is completely restricted in a confluent monolayer. When ECs are plated sparsely or when a confluent culture is "wounded," a large percentage of cells begin to migrate and enter the cell cycle. Our current studies do not distinguish between a role for EC migration vs. proliferation in monocyte binding although preliminary results in our laboratory indicate that entrance into the cell cycle may be important in the expression of monocyte binding sites. It should be pointed out that in all of our reported experiments, target cells were trypsinized and used within $48 \mathrm{~h}$ of plating. DeBono and Green (22) have reported a decline in peritoneal macrophage adherence with the length of time an EC culture has been maintained since plating. Our own preliminary studies indicate that U937 cell binding sites on ECs may also be reduced with time in culture.

In summary, we have described a model system for monocyte adhesion to the endothelium which exhibits several properties consistent not only with experiments in vitro using normal blood monocytes but with observations by others in vivo on monocyte attachment to the vessel wall. The model system should be helpful in answering mechanistic questions regarding cell-cell attachment under completely defined conditions.

\section{Acknowledgments}

We thank Ms. Pat Blue and Dr. Ross Gerrity for providing assistance in the centrifugal elutriation method and in the staining and differential counting of leukocytes. In addition, we are grateful to Dr. Guy Chisolm for helpful discussions during the course of the work and critical review of the manuscript, and to Dr. Martha Cathcart for providing the U937 cells (American Type Culture Collection). Mr. Endre Ritly and Ms. Muriel Daly provided excellent photographic and secretarial assistance.

This work was supported by a grant from the National Heart,
Lung and Blood Institute, National Institutes of Health (NIH) (HL29582). Human foreskin fibroblasts and human umbilical vein ECs were prepared from tissue provided by the Perinatal Clinical Research Center (NIH U. S. Public Heath Service MO1 RR00210), Cleveland Metropolitan General Hospital.

\section{References}

1. Still, W. J. S., and R. M. O'Neal. 1962. Electron microscopic study of experimental atherosclerosis in the rat. Am. J. Pathol. 40:2135 .

2. Joris, I., and G. Majno. 1979. Inflammatory components of atherosclerosis. Adv. Inflammation Res. 1:71-85.

3. Fowler, S. 1980. Characterization of foam cells in experimental atherosclerosis. Acta Med. Scand. 642(Suppl.):151-158.

4. Ross, R. 1981. Atherosclerosis: a problem of the biology of the arterial wall cells and their interactions with blood components. Arteriosclerosis. 1:293-311.

5. Cookson, F. B. 1971. The origin of foam cells in atherosclerosis. Br. J. Exp. Pathol. 52:62-69.

6. Fowler, S., H. Shio, and N. J. Haley. 1979. Characterization of lipid-laden aortic cells from cholesterol-fed rabbits. IV. Investigation of macrophage-like properties of aortic cell populations. Lab. Invest. 41:372-378.

7. Gerrity, R. G., and H. K. Naito. 1980. Ultrastructural identifcation of monocyte-derived foam cells in fatty streak lesions. Artery. 8:208-214.

8. Glenn, K. C., and R. Ross. 1981. Human monocyte-derived growth factors for mesenchymal cells: activation of secretion by endotoxin and concanavalin A. Cell. 25:603-615.

9. Martin, B. M., M. A. Gimbrone, Jr., G. R. Majeau, E. R. Unanue, and R. S. Cotran. 1983. Stimulation of human monocyte/ macrophage-derived growth factor (MDGF) production by plasma fibronectin. Am. J. Pathol. 111:367-373.

10. Cathcart, M. K., D. W. Morel, and G. M. Chisolm. 1985. Monocytes and neutrophils oxidize low density lipoprotein making it cytotoxic. J. Leuk. Biol. In press.

11. Gerrity, R. G. 1981. The role of the monocyte in atherogenesis. II. Migration of foam cells from atherosclerotic lesions. Am. J. Pathol. 103:191-200.

12. Gerrity, R. G. 1981. The role of the monocyte in atherogenesis. I. Transition of blood-borne monocytes into foam cells in fatty lesions. Am. J. Pathol. 103:181-190.

13. Faggioto, A., R. Ross, and L. Harker. 1984. Studies of hypercholesterolemia in nonhuman primates. I. Changes that lead to fatty streak formation. Arteriosclerosis. 4:323-340.

14. Joris, I., T. Zand, J. J. Nunnari, F. J. Krolikowski, and G. Majno. 1983. Studies on the pathogenesis of atherosclerosis. I. Adhesion and emigration of mononuclear cells in the aorta of hypercholesterolemic rats. Am. J. Pathol. 113:341-358.

15. Lewis, J. C., R. G. Taylor, N. D. Jones, R. W. St. Clair, and J. F. Cornhill. 1982. Endothelial surface characteristics in pigeon coronary artery atherosclerosis. I. Cellular alterations during the initial stages of dietary cholesterol challenge. Lab. Invest. 46:123-138.

16. Beesby, J. E., J. D. Pearson, J. S. Carleton, A. Hutchings, and J. L. Gordon. 1979. Interaction of leukocytes with vascular cells in culture. J. Cell Sci. 38:225-232.

17. Zweiman, B., A. R. Moskovitz, and R. P. Lisak. 1982. Quantitative assessment of the adherence of normal human blood mononuclear cells to vascular endothelial cell monolayers. Cell. Immunol. 68:165-172.

18. Sedgwick, A. D., A. R. Mackay, M. B. Bates, and D. A. Willoughby. 1983. The role of plasma factors in the adherence of leukocytes to vascular endothelial cells. J. Pathol. 140:9-16.

19. Hoover, R. L., R. T. Briggs, and M. J. Karnovsky. 1978. The 
adhesive interaction between polymorphonuclear leukocytes and endothelial cells in vitro. Cell. 14:423-428.

20. Boogaerts, M. A., O. Yamada, H. S. Jacob, and C. F. Moldow. 1982. Enhancement of granulocyte-endothelial cell adherence and granulocyte-induced cytotoxicity by platelet release products. Proc. Natl. Acad. Sci. USA. 79:7019-7023.

21. Buchanan, M. R., M. J. Vasquez, and M. A. Gimbrone, Jr. 1983. Arachidonic acid metabolism and the adhesion of human polymorphonuclear leukocytes to cultured vascular endothelial cells. Blood. 62:889-895.

22. DeBono, D. P., and C. Green. 1984. The adhesion of different cell types to cultured vascular endothelium: effects of culture density and age. Br. J. Exp. Pathol. 65:145-154.

23. Savion, N., I. Vlodavsky, and Z. Fuks. 1984. Interaction of $T$ lymphocytes and macrophages with cultured vascular endothelial cells: attachment, invasion, and subsequent degradation of the subendothelial extracellular matrix. J. Cell. Physiol. 118:169-178.

24. Sundstrom, C., and K. Nilsson. 1976. Establishment and characterization of a human histiocytic lymphoma cell line (U-937) Int. J. Cancer. 17:565-577.

25. Fischer, D. G., M. C. Pike, H. S. Koren, and R. Snyderman. 1980. Chemotactically responsive and nonresponsive forms of a continuous human monocyte cell line. J. Immunol. 125:463-465.

26. DiCorleto, P. E., and D. F. Bowen-Pope. 1983. Cultured endothelial cells produce a platelet-derived growth factor-like protein. Proc. Natl. Acad. Sci. USA. 80:1919-1923.

27. Ross, R. 1971. The smooth muscle cell. II. Growth of smooth muscle in culture and formation of elastic fibers. J. Cell Biol. 50:172186.

28. Boyum, A. 1968. Isolation of mononuclear cells and granulocytes from human blood. Scand. J. Clin. Lab. Invest. 21(Suppl. 97):77-83.

29. Sanderson, R. J. 1982. Separation of different kinds of nucleated cells from blood by centrifugal elutriation. In Cell Separation. Methods and Selected Applications. Vol. 1. 153-168.

30. Stevenson, H. C., P. Miller, Y. Akiyama, T. Favilla, J. A. Berman, R. Heberman, H. Stull, G. Thurman, A. Maluish, and R. Oldham. 1983. A system for obtaining large numbers of cryopreserved human monocytes purified by leukapheresis and countercurrent centrifugation elutriation (CCE). J. Immunol. Methods. 62:353-363.
31. Stossel, T. P., T. D. Pollard, R. J. Mason, and M. Vaughan. 1971. Isolation and properties of phagocytic vesicles from polymorphonuclear leukocytes. J. Clin. Invest. 50:1745-1757.

32. Gospodarowicz, D., and C. R. Ill. 1980. The extracellular matrix and the control of proliferation of vascular endothelial cells. $J$. Clin. Invest. 65:1351-1364.

33. Bevilacqua, M. P., R. S. Cotran, G. R. Majeau, J. S. Pober, and M. A. Gimbrone, Jr. 1984. Adhesion of a human monocyte-like cell line (U937) to vascular endothelium. Fed. Proc. 43:459. (Abstr.)

34. Vlodavsky, I., Z. Fuks, and V. Schirrmacher. 1983. In vitro studies on tumor cell interaction with the vascular endothelium and the subendothelium basal lamina: Relationship to tumor cell metastasis. In The Endothelial Cell-A Pluripotent Control Cell of the Vessel Wall. D. G. S. Thilo-Korner and R. I. Freshney, editors. S. Karger, Basel. 126-157.

35. Bowen-Pope, D. F., and R. Ross. 1982. Platelet-derived growth factor. II. Specific binding to cultured cells. J. Biol. Chem. 257:51615171.

36. Ladda, R. L., L. P. Bullock, T. Gianopoulos, and L. McCormick. 1979. Radioreceptor assay for epidermal growth factor. Anal. Biochem. 93:286-294.

37. Jauchem, J. R., M. Lopez, E. A. Sprague, and C. J. Schwartz. 1982. Mononuclear cell chemoattractant activity from cultured arterial smooth muscle cells. Exp. Mol. Pathol. 37:166-174.

38. Gerrity, R. G., J. A. Goss, and L. Soby. 1985. Control of monocyte recruitment by chemotactic factor(s) in lesion-prone areas of swine aorta. Arteriosclerosis. 5:55-66.

39. Gerrity, R. G., and C. J. Schwartz. 1977. Endothelial cell injury in early mild hypercholesterolemia. Prog. Biochem. Pharmacol. 14:213-219.

40. Hansson, G. K., T. Bjornheden, A. Bylock, and G. Bondjers. 1981. Fc-dependent binding of monocytes to areas with endothelial injury in the rabbit aorta. Exp. Mol. Pathol. 34:264-280.

41. Walker, L. N., and D. E. Bowyer. 1984. Endothelial healing in the rabbit aorta and the effect of risk factors for atherosclerosis. Hypercholesterolemia. Arteriosclerosis. 4:479-488.

42. Schwartz, S. M., C. M. Gajdusek, and S. C. Selden III. 1981. Vascular wall growth control: the role of the endothelium. Arteriosclerosis. 1:107-161. 